Hong-Xia Chen

Guang-Jun Jiang $\bowtie$

Le Gao

https://doi.org/10.21278/TOF.43Si103

ISSN 1333-1124

eISSN 1849-1391

\title{
NUMERICAL SIMULATION STUDY OF TURBULENT FLOW IN VACUUM TEMPERING FURNACE USING K-EPSILON MODEL
}

\begin{abstract}
Summary
Vacuum tempering furnace prevalence of uneven temperature problems. In this paper, numerical analyses for turbulent flow inside vacuum tempering furnace using $\mathrm{k}-\varepsilon$ turbulence model. The moving reference frame is helpful to improve the precision of the model. Not only the loading area and its adjacent components have an influence on temperature uniformity, but the shape of the auxiliary parts, the shape of the driving parts and the way of loading have an influence. The influence factors of turbulence are studied from multiple angles. Based on the factors, the combinatorial optimization scheme is proposed and temperature uniformity test is carried out. The results show that the shape of the fan blade, the inlet diameter of the gas guide tube, the shape of the centre channel and the shape of the wind scooper influences furnace temperature uniformity. The adjustment of loading area and the use of multiple central channels in equal area will not affect furnace temperature uniformity.
\end{abstract}

Key words: $\quad$ Flow field analysis; K-epsilon model; Influence factor; Temperature uniformity test

\section{Introduction}

Niu YanFeng et al. found that flow structure of the TBCC exhaust system is complicated because the two exhaust jet streams interact with each other around the exit plane of the turbo [1]. Hamed and Saeid used k- $\varepsilon$ turbulence model to study the effect of shape of a circular channel on the pattern and intensity of a secondary flow in the main channel [2]. By numerical simulation, the deviation of the velocity and the concentration fields in willow leaflike static mixer were reached to ideal range [3]. Huang ZheQing et al. used the standard k- $\varepsilon$ turbulence model to simulate poly-crystalline silicon reduction furnace and found that the use of flat flow can control the temperature field in the furnace $[4,5]$. The results can solve the problem of furnace temperature uniformity and reduce the power consumption of reduction furnace. Huang et al. studied the internal flow field and oil-water separation performance of a rotary hydrocyclone [6]. Rotation speed and flow rate are the affecting factors of the velocity profile. The separation efficiency can be improved by increasing rotation speed and decreasing the flow rate. Liu Yu-Jia et al. wielded the standard k- $\varepsilon$ turbulence model to study 
the combustion timing control scheme of burner for heat furnace, which provided a reference for solving furnace temperature uniformity problem [7, 8]. Wang Ji-Ming et al. also wielded the standard $\mathrm{k}-\varepsilon$ turbulence model to study melting furnace to solve furnace temperature uniformity problem [9-11]. Forrt et al. studied the flow field in a turbine cascade using $\mathrm{k}-\omega$ turbulence model [12]. The paper proposed a proper numerical approximation of boundary conditions suitable for cases with supersonic inlet and outlet flow velocities. A research on the factors of combustion chamber performance had been conducted based on the Realizable k- $\varepsilon$ turbulence model. The performance of the combustion chamber was reached to ideal level $[13,14]$. J. J. Kim et al. wielded the RNG k- $\varepsilon$ model to study the turbulent flow of heat furnaces, and achieved a lot of valuable results [15-18].

The coordinate system is established in the prior studies, but an inertial coordinate system will be established in this paper. It will affect the accuracy of the results. There is no consideration of the effects of some factors on the turbulence, such as the shape of the auxiliary parts, the shape of the driving parts, and the way of loading, and so on. Therefore, this paper establishes an inertial frame and a moving reference frame at the same time. The influence factors of turbulence are studied from multiple angles.

\section{Material and Methods}

\subsection{Material}

The vacuum furnace has the following characteristics. Compared to other processes such as quenching or annealing, the working temperature of vacuum furnace is generally below $700^{\circ} \mathrm{C}$.Vacuum furnace mainly rely on heat radiation in a vacuum state, but the heating efficiency is low. Therefore, vacuum furnace generally is used the method of gas heating to improve the heating efficiency. Because gas flow is less affected, furnace temperature uniformity can also ensure under the case of no-load. But furnace temperature uniformity is difficult to guarantee under the case of full-load.

\subsection{Methods}

\subsubsection{Modeling assumptions}

Vacuum furnace is assumed to be $550^{\circ} \mathrm{C}$ isothermal environment, and neglect the heat transfer process and flow caused by uneven temperature. The temperature and pressure are not high enough, so nitrogen can be set as an ideal gas. The middle hole of the right wind scooper, where the rate of flow is slow and far from the centre, has little effect on flow, so the hole can be neglected. The gas guide tube, guide vane and fan blade are all thin-walled component, so the thickness is neglected. The loading area has about 5000 work-pieces. If the details of work-piece are neglected, the loading area is considered a porous medium. The $200 * 200 \mathrm{~mm}^{2}$ centre channel is also considered a porous medium due to the impact of the net. The flow at work is considered steady state, and neglected the start-up process of fan.

\subsubsection{Physical model}

The whole model is divided into fan area and furnace body. The direction of the fan area is along the $\mathrm{X}$ axis using a moving reference frame, and furnace body is an inertial frame. As an ideal gas, the pressure of nitrogen sets 1.5 bar is other mal temperature of vacuum furnace sets $550^{\circ} \mathrm{C}$. Because the average speed of the central loading area is slow, the pressure loss can be approximated as linear relationship with speed. The 3D model of furnace is established as shown in fig. 1 . 

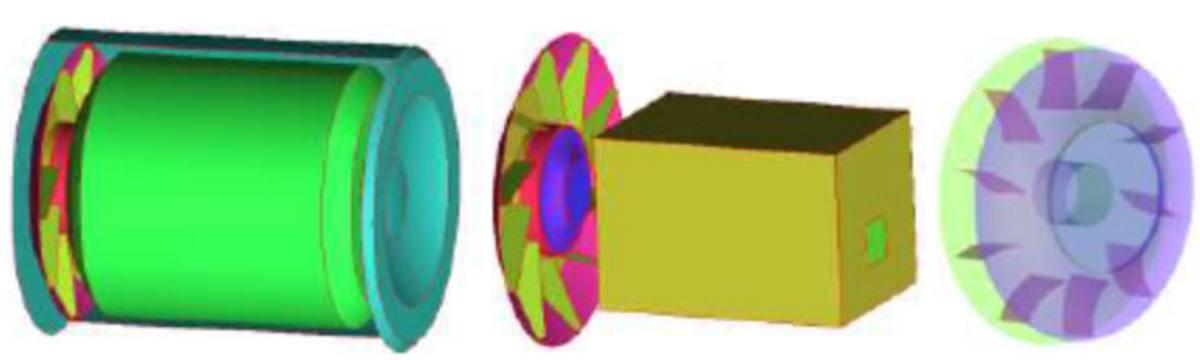

Fig. $13 \mathrm{D}$ model for furnace structure.

\subsubsection{Governing equation}

The governing equation consists of four parts: continuity equation, N-S equation, energy equation and other equations, which can be expressed in general form

$$
\frac{\partial(\rho \phi)}{\partial t}+\operatorname{div}(\rho u \phi)=\operatorname{div}(\Gamma \operatorname{grad} \phi)+S
$$

where each of the Equation (1) represents transient term, convective term, diffusion term and source term. Here, $\phi$ is the general variable, $\Gamma$ the generalized diffusion coefficient, $S$ the generalized source term. Its expansion is given by

$$
\frac{\partial(\rho \phi)}{\partial t}+\frac{\partial(\rho u \phi)}{\partial x}+\frac{\partial(\rho w \phi)}{\partial z}=\frac{\partial}{\partial x}\left(\Gamma \frac{\partial \phi}{\partial x}\right)+\frac{\partial}{\partial y}\left(\Gamma \frac{\partial \phi}{\partial y}\right)+\frac{\partial}{\partial z}\left(\Gamma \frac{\partial \phi}{\partial z}\right)
$$

\subsubsection{Moving reference frame model}

The flow problem of fan needs to use moving reference frame model. The physical process of rotation can be described more accurately by establishing a rotating coordinate that is consistent with the rotating equipment. The momentum equation of a rotating coordinate is described as

$$
\frac{\partial(\rho U)}{\partial t}+\nabla \cdot(\rho U U)=\nabla(\mu \operatorname{grad} U)+S-\rho(\Omega \times U)
$$

Here, $U$ is absolute speed, and $\Omega$ is angular velocity vector.

\subsubsection{Turbulence model}

In this paper, we use the standard $k$ - $\varepsilon$ model, which is widely used in engineering [6]. The standard k- $\varepsilon$ model represents the turbulent viscosity $\mu_{t}$ by the turbulent kinetic energy $k$ and the turbulent dissipation rate $\varepsilon$

$$
\mu_{t}=\rho C_{\mu} \frac{k^{2}}{\varepsilon}
$$

Turbulent quantities can be derived from the flowing transport equation for $k$

$$
\frac{\partial(\rho k)}{\partial t}+\frac{\partial\left(\rho k \mu_{i}\right)}{\partial x_{i}}=\frac{\partial}{\partial x_{j}}\left[\left(\mu+\frac{\mu_{t}}{\sigma_{k}}\right) \frac{\partial k}{\partial x_{j}}\right]+G_{k}-\rho \varepsilon
$$

and for $\varepsilon$

$$
\frac{\partial(\rho \varepsilon)}{\partial t}+\frac{\partial\left(\rho \varepsilon \mu_{i}\right)}{\partial x_{i}}=\frac{\partial}{\partial x_{j}}\left[\left(\mu+\frac{\mu_{t}}{\sigma_{\varepsilon}}\right) \frac{\partial \varepsilon}{\partial x_{j}}\right]+\frac{C_{1 \varepsilon}}{k} G_{k}-C_{2 \varepsilon} \rho \frac{\varepsilon^{2}}{k}
$$

where $G_{k}$ said the turbulent kinetic energy $k$ caused by the average velocity gradient. Here, $\rho$ the fluid density, $k$ the thermal conductivity, $u_{i}$ the component of gas velocity. $C_{1 \varepsilon}=1.44$ and $C_{2 \varepsilon}=1.92$ are constants, $\sigma_{\mathrm{k}}=1.0, \sigma_{\varepsilon}=1.3$ are the turbulent Prandtl numbers by $k$ and $\varepsilon$. 
H.X. Chen, G.J. Jiang, L. Gao
Numerical Simulation Study of Turbulent Flow in Vacuum Tempering Furnace Using K-Epsilon Model

\subsubsection{Boundary condition}

For the wall of the furnace, gas guide tube, guide vanes, the wall of fan and all the other vanes, no-slip wall conditions were set. Rated speed of fan is set with $1460 \mathrm{rpm}$. Wallfunction method is employed to the wall. Material properties are set according to actual usage.

\subsubsection{Computational meshes}

Unstructured grid distribution is used in this paper, considering the complexity of the vacuum furnace, in order to make the grid more suitable for structure [12]. The model is divided into multiple regions due to moving reference frame. The grid interface between adjacent regions is set to 'Interface'. The grid of complex positions is dense to improve the precision and quality. 2 test points, as shown in Fig. 2 (a), are selected in the centre of loading area and the gas guide tube. The flow velocity of test points is shown in Fig. 2 (b) under different number of nodes. When the number of nodes is 481,573 , the grid division reaches the ideal level. After the model is divided, 480 thousand nodes and 2.07 million units are obtained. The minimum grid size is $9 \mathrm{~mm}$. The iteration time step is 0.0001 . The computing time is $27.9 \mathrm{~s}$.

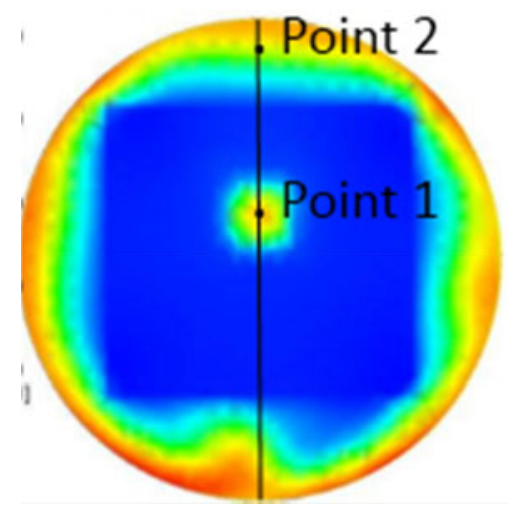

(a)

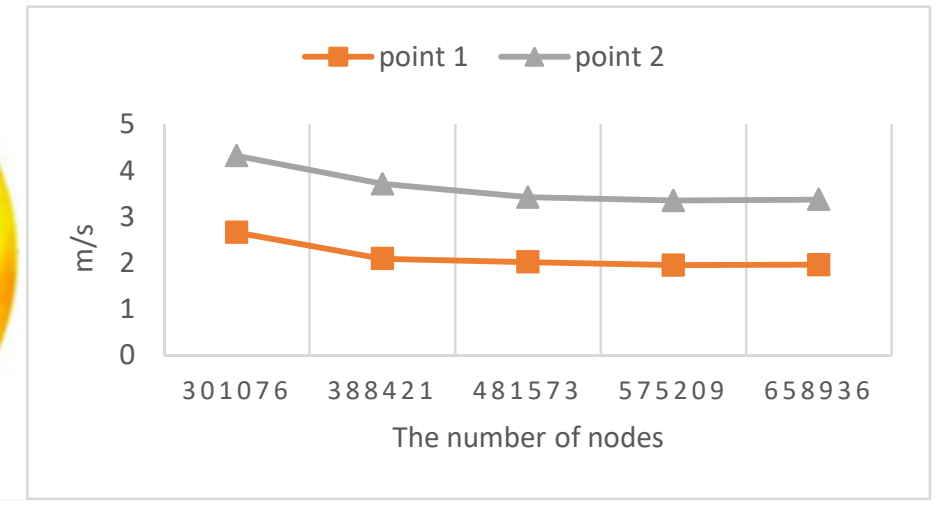

(b)

Fig. 2 The location and test data of points for grid independence test.

\section{Results}

CFD software CFX is used to analyse and calculate the model, and got the simulated results. Fig. 3 shows 8 main cross sections of turbulent flow. The intercepting way is based on the vacuum furnace structure.

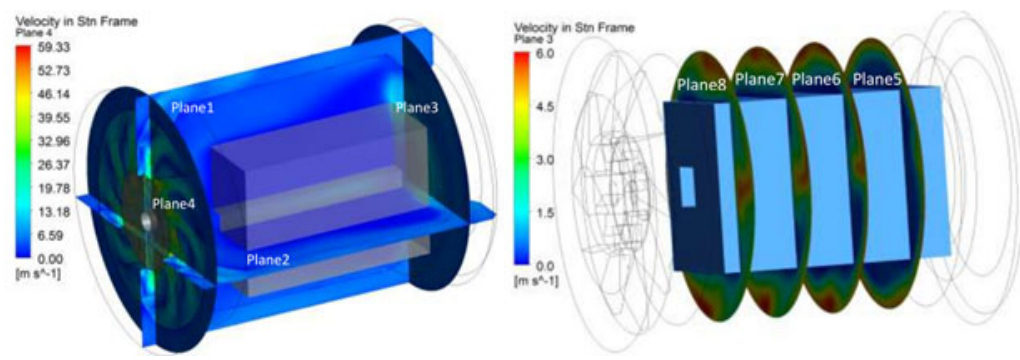

Fig. 3 The intercepting way of cross sections.

The initial simulated results are shown in Fig. 4. It can be observed that the flow velocity of around is much greater than the central. The reason for the problem of the furnace temperature uniformity is that convective heat transfer is insufficient at the current velocity of central part. 

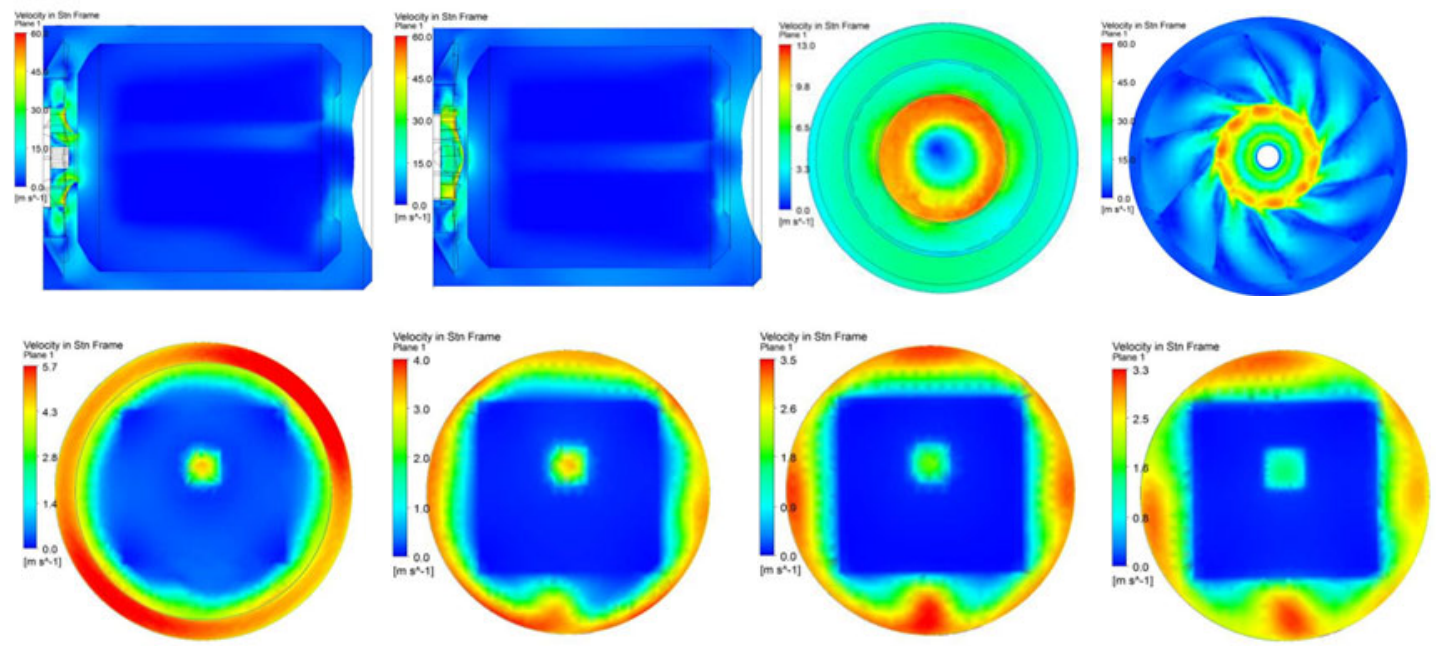

Fig. 4 Initial simulated results

\section{Discussion}

\subsection{Analysis}

For a plane with little change in velocity, it is no longer shown here. The results of the simulation using a cylindrical guide vane are shown in Fig. 5 (a). Its cross section is plane 5, 6, 7 and 8. It can be observed that the flow velocity around loading area was increased significantly, while the flow velocity of the central part was not increased significantly. Fig 5(b) represents the simulation results of reducing inlet diameter of the gas guide tube on the right side. Its cross section is plane 3, 5, 6 and 8. Fig 5(c) represents the simulated results of changing the shape of centre channel to round. Its cross section is plane 4, 6, 7 and 8 . Fig 5(d) represents the simulated results of changing the ellipsoidal surface of the right side of the furnace wall to the conical surface. Its cross section is plane 3,6,7 and 8 . It can be observed that the flow velocity of the central part was increased significantly, while the surrounding flow velocity was not increased significantly in the case of three kinds of structural adjustment. In addition, using the multiple central channels in equal area and adjusting the location of loading area has minor influences on turbulent flow.
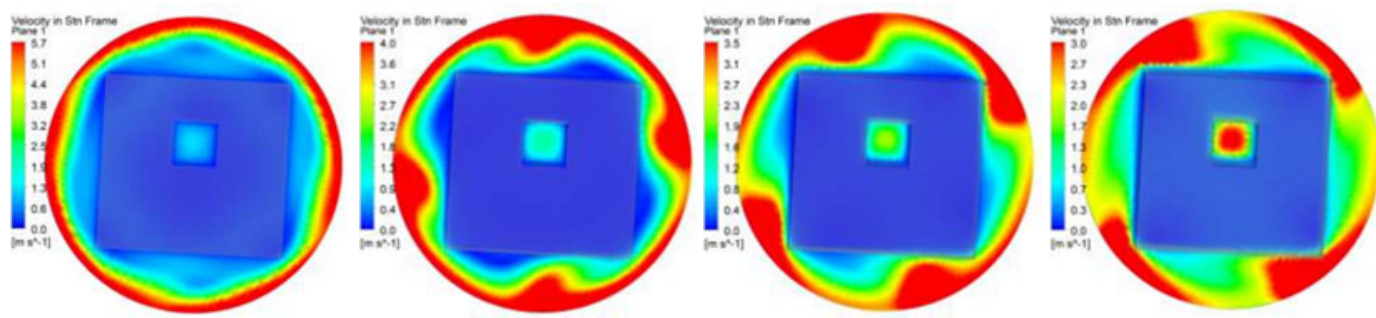

(a) Cylindrical guide vane
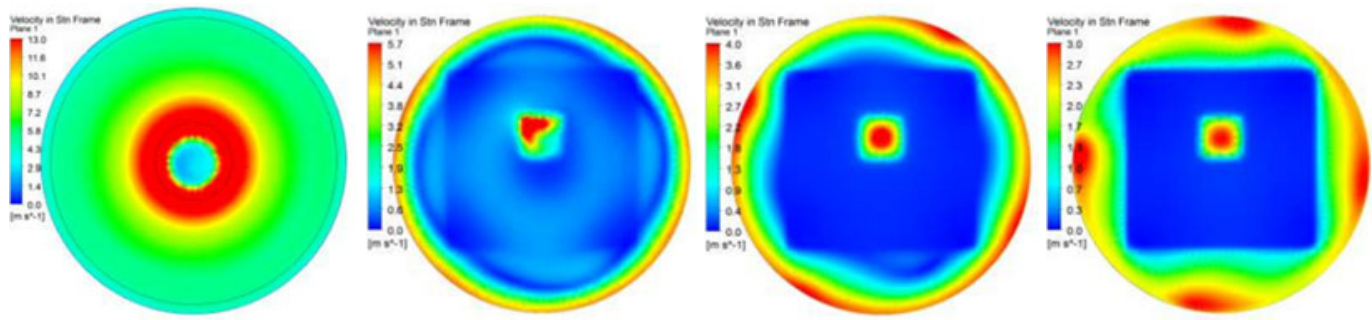

(b) Reduce inlet diameter 
H.X. Chen, G.J. Jiang, L. Gao
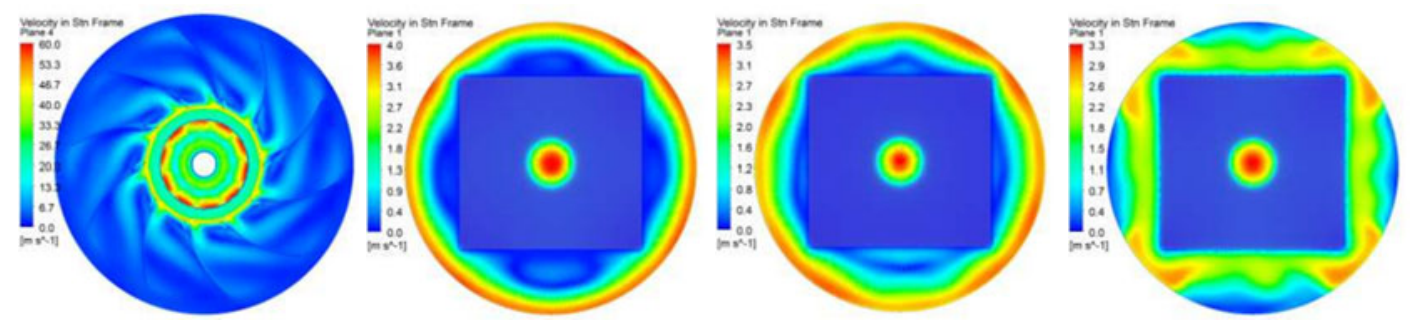

(c) Circular centre channel
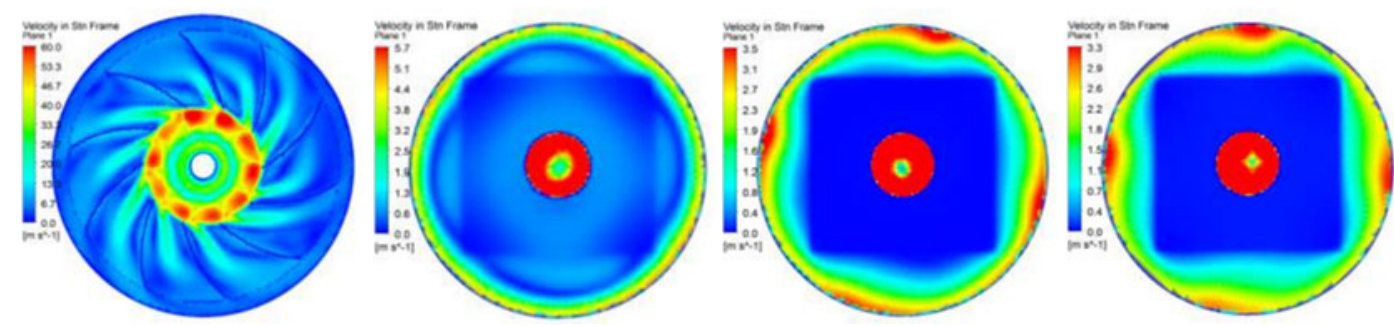

(d) Use conical surface

Fig. 5 The simulation results that changes a variety of structures

\subsection{Structural optimization}

According to the above analysis results, the combined optimization scheme of vacuum furnace is designed. The cylindrical guide vane has been used for models $6-48 \mathrm{~N} 5 \#$ as shown in Fig.6(a); the wind-cover on the right side, which was replaced with a new one, was changed to the conical surface as shown in Fig.6(b). The inlet diameter of the gas guide tube was reduced by $700 \mathrm{~mm}$ to $500 \mathrm{~mm}$. The change in the inlet of the guide tube is shown in Fig.6(c). The square centre channel was changed into a circular channel with a diameter of $300 \mathrm{~mm}$. The new gas guide tube is replaced due to the limitation of the current one, and was drilled into a hole with a diameter of $300 \mathrm{~mm}$.

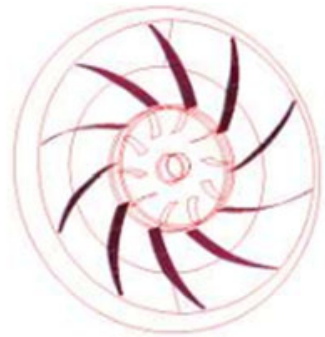

(a) Cylindrical guide vane.

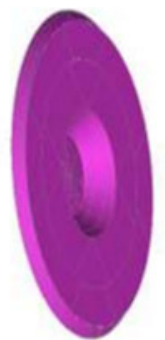

(b) New wind scooper.

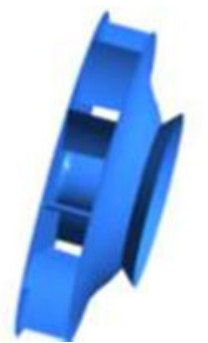

(c) Gas guide tube.

Fig. 6 Engineering drawings of parts

\subsection{Temperature uniformity test}

The furnace temperature uniformity have to be tested to confirm whether the furnace meets the requirements of the heat treatment process after the furnace is repaired, before it is purchased, or if the position of heating element was changed. In this case, the test is conducted to confirm whether the furnace temperature uniformity is improved after undertaken structural optimization. At present, there are three main methods for measuring furnace uniformity: displacement method, differential method and multi-point measurement method [19-21]. Displacement method and differential method have impact for turbulent flow due to the movement of thermo-couple, and the test need a long time. Multi-point measurement method 
has the characteristics of accurate positioning, short test time, high accuracy, the least impact on the results, so the test method of this paper selected multi-point measurement method. This paper sets sensor and calculates temperature difference according to AMS2750D. The sensor is located at the centre and 8 vertices of the cuboid loading area. The measurements were performed for nominal furnace temperatures of $300^{\circ} \mathrm{C}, 450^{\circ} \mathrm{C}$ and $600^{\circ} \mathrm{C}$. The experimental data are collected after measurement, as shown in table 1 and table 2.

Table 1 Deviation

\begin{tabular}{|c|c|c|}
\hline Set point & Before & After \\
\hline $300^{\circ} \mathrm{C}$ & $-12.9 \sim 3.7$ & $-3.4 \sim 3.3$ \\
\hline $450^{\circ} \mathrm{C}$ & $-16.0 \sim 4.0$ & $-4.7 \sim 4.2$ \\
\hline $600^{\circ} \mathrm{C}$ & $-17.2 \sim 5.4$ & $-6.2 \sim 5.6$ \\
\hline
\end{tabular}

Table 2 Experimental data summary

\begin{tabular}{|c|c|c|c|c|c|c|c|c|c|c|c|c|c|}
\hline \multirow{2}{*}{ Category } & \multirow{2}{*}{ Set point } & \multirow{2}{*}{ Time } & \multirow{2}{*}{ Channel } & \multicolumn{10}{|c|}{ Corrected } \\
\hline & & & & $\mathrm{CH} 01$ & $\mathrm{CH} 02$ & $\mathrm{CH} 03$ & $\mathrm{CH} 04$ & $\mathrm{CH} 05$ & $\mathrm{CH} 06$ & $\mathrm{CH} 07$ & $\mathrm{CH} 08$ & CH09 & Deviation \\
\hline \multirow{6}{*}{ Before } & \multirow{2}{*}{$300^{\circ} \mathrm{C}$} & $13: 46$ & Max & 296.6 & 301.4 & 299.0 & 297.1 & 299.2 & 303.7 & 302.5 & 303.5 & 288.8 & 3.7 \\
\hline & & $14: 16$ & Min & 295.4 & 300.7 & 298.1 & 296.3 & 297.8 & \begin{tabular}{|l|}
303.2 \\
\end{tabular} & 301.8 & 302.8 & 287.1 & -12.9 \\
\hline & \multirow{2}{*}{$450^{\circ} \mathrm{C}$} & $15: 16$ & Max & 441.6 & 453.5 & 448.2 & 446.0 & 445.9 & 454.0 & 452.6 & 449.8 & 435.6 & 4.0 \\
\hline & & $15: 46$ & Min & 440.6 & 452.8 & 447.1 & 445.2 & 445.3 & 453.7 & 452.0 & 449.3 & 434.0 & -16.0 \\
\hline & \multirow{2}{*}{$600^{\circ} \mathrm{C}$} & $16: 46$ & Max & 584.7 & 603.2 & 597.2 & 598.8 & 594.6 & 605.4 & 603.0 & 598.5 & 586.4 & 5.4 \\
\hline & & $17: 16$ & Min & 582.8 & 601.7 & 595.6 & 597.5 & 594.1 & 605.0 & 602.3 & 597.9 & 585.1 & -17.2 \\
\hline \multirow{6}{*}{ After } & \multirow{2}{*}{$300^{\circ} \mathrm{C}$} & $13: 20$ & Max & 297.6 & 301.4 & 299.2 & 297.1 & 298.2 & 302.7 & 302.5 & 303.3 & 296.8 & 3.3 \\
\hline & & $13: 50$ & Min & 297.4 & 300.9 & 299.1 & 296.8 & 297.8 & 302.2 & 301.7 & 302.9 & 296.6 & -3.4 \\
\hline & \multirow{2}{*}{$450^{\circ} \mathrm{C}$} & $14: 50$ & Max & 446.6 & 452.5 & 448.5 & 446.6 & 445.8 & 454.2 & 452.8 & 449.7 & 446.6 & 4.2 \\
\hline & & 15:20 & Min & 445.6 & 451.8 & 447.9 & 446.2 & 445.3 & 453.6 & 452.1 & 449.3 & 446.0 & -4.7 \\
\hline & \multirow{2}{*}{$600^{\circ} \mathrm{C}$} & $16: 20$ & Max & \begin{tabular}{|l|}
594.7 \\
\end{tabular} & \begin{tabular}{|l|}
603.2 \\
\end{tabular} & \begin{tabular}{|l|}
597.2 \\
\end{tabular} & 598.5 & 595.5 & 605.6 & 602.9 & 598.6 & 594.7 & 5.6 \\
\hline & & $16: 50$ & Min & 593.8 & 602.7 & 596.3 & 597.9 & \begin{tabular}{|l|}
594.8 \\
\end{tabular} & \begin{tabular}{|l}
605.2 \\
\end{tabular} & 602.1 & 598.2 & 594.1 & -6.2 \\
\hline
\end{tabular}

The results shown that the deviation, compare before and after using the combined optimization scheme, are $\pm 20^{\circ} \mathrm{C}$ and $\pm 10^{\circ} \mathrm{C}$ respectively. The temperature uniformity in the furnace has improved.

\section{Conclusions}

This paper studies turbulent flow in vacuum tempering furnace to solve the problem of temperature uniformity. It is based on the standard $\mathrm{k}-\varepsilon$ model. The moving reference frame model is set up for the fan blade. The inertial reference frame is set up for other region. The influence factors of turbulence flow are studied from multiple angles, such as driving part, auxiliary component and the way of loading. The factors of temperature uniformity are obtained through analysing the simulated results. The combined optimization scheme is proposed and the temperature uniformity of the vacuum furnace is tested.

To conclude, the turbulent flow around loading area is increased significantly when using a cylindrical guide vane, but the increase of turbulence in the central region is not obvious. When reducing inlet diameter of the gas guide tube, changing the shape of centre channel to round and changing the ellipsoidal surface of the right side of the furnace wall to the conical surface, the turbulent flow in the central region is increased significantly. centre In addition, using the multiple central channels in equal area and adjusting the location of loading area has hardly influence on turbulent flow under certain conditions. It can be seen that the uniformity problem of this type of vacuum tempering furnace is effectively solved. 
H.X. Chen, G.J. Jiang, L. Gao
Numerical Simulation Study of Turbulent Flow in Vacuum Tempering Furnace Using K-Epsilon Model

\section{Acknowledgments}

This work was partially supported by the National Natural Science Foundation of China under the contract number 71761030.

\section{REFERENCES}

[1] Niu, Y, F.; Xu, J, L.; Xu, B, C.; Chen, K, S.; Numerical and Experimental Study of Over-Under TBCC Exhaust System Flow Structure, Journal of Propulsion Technology 2017, 38(12), 2686-2691. http://dx.doi.org/10.13675/j.cnki.tjjs.2017.12.006. (in Chinese)

[2] Hamed, A.; Saeid, S.; Numerical Simulation of Free Surface and Flow Field Turbulence in a Circular Channel with the Side Weir in Subcritical Flow, International Journal of Nonlinear Sciences and Numerical Simulation 2017, 18(3-4), 255-267. https://doi.org/10.1515/ijnsns-2016-0115

[3] Fu, X, L.; Yan, Z, Y.; Flow and mixing characteristics in willow leaf-like static mixer, CIESC Journal 2017, 68(12), 4600-4606. (in Chinese)

[4] Huang, Z, Q.; Liu, C, J.; Yuan, X J.; Numerical simulation of flow and heat transfer in a novel polysilicon reduction furnace, Journal of Chemical Industry and Engineering (China) 2013, 64(02), 484-489. http://dx.doi.org/10.3969/j.issn.0438-1157.2013.02.011. (in Chinese)

[5] Zhou, Y.; Duan, L.; Huang, Z, Q.; Liu, C, J.; Numerical Simulation of Flow and Heat Transfer in a Novel Polysilicon Reduction Furnace's Baseboard, Chemical Industry and Engineering 2015, 32(01), 41-47. http://dx.doi.org/10.13353/j.issn.1004.9533.2015.01.009. (in Chinese)

[6] Huang, L.; Deng, S, S.; Chen, M.; Guan, J, F.; Numerical simulation and experimental study on a deoiling rotary hydrocyclone, Chemical Engineering Science 2017, 172(23), 107-116. https://doi.org/10.1016/j.ces.2017.06.030

[7] Liu, Y, J.; Li, Y.; Fu, T, L.; Li, J, D.; Hou, S.; Wang, Z, D.; Wang, G, D.; Simulation of roller hearth heat treatment furnace based on Fluent software. Jinshu Rechuli/Heat Treatment of Metals. 39. 128-131. http://dx.doi.org/10.13251/j.issn.0254-6051.2014.08.034. (in Chinese)

[8] Liu, Y, J.; Li, Y.; Wang, Z, D.; Wang, G, D.; Study on the roller heat-treatment furnace burner control, Chinese Journal of Computational Mechanics 2015, 32(06), 820-824.

http://dx.doi.org/10.7511/jslx201506017. (in Chinese)

[9] Wang, J, M.; Yan, H, J.; Zhou, J, M.; Li, S, X.; Gui, G, C.; Numerical simulation and optimizing combination of aluminum melting furnace linings, Journal of Central South University of Science and Technology 2012, 43(04), 1523-1531.

[10] Xu, P.; Wang, J, M.; Li, W, K.; Numerical simulation of thermal behaviors of an aluminum holding furnace, Light Metals 2014, (01), 32-37. http://dx.doi.org/10.13662/j.cnki.qjs.2014.01.008. (in Chinese)

[11] Zhou, J.; Wang, C.; Zhu, J.; Multi-Objective Optimization of a Spring Diaphragm Clutch on an Automobile Based on the Non-Dominated Sorting Genetic Algorithm (NSGA-II), Mathematical and Computational Applications, 2016, 21(4). https://doi.org/10.20944/preprints201611.0139.v1

[12] Fořt, J.; Fürst, J.; Halama, J.; Hric, V.; Louda, P.; Luxa, M.; Šimurda, D.; Numerical simulation of flow through cascade in wind tunnel test section and stand-alone configurations, Applied Mathematics and Computation 2017, 319(15), 633-646. https://doi.org/10.1016/j.amc.2017.07.040

[13] Wang, Y, M.; Fang, X, J.; Gu, H, B.; Lin, P.; Wang, X.; Investigation of Hot Air on Performance of Ramjet Combustor, Journal of Propulsion Technology 2017, 38(12), 2778-2787. http://dx.doi.org/10.13675/j.cnki.tjjs.2017.12.017. (in Chinese)

[14] He, W.; Guo, Z, H.; Zhao, X, C.; Shao, F, Y.; Jiang, X, hui.; Wu, J.; Design Investigation of Annular Combustor with Slinger and Compacted Effusion Cooling Holes, Journal of Propulsion Technology, 2017, 38(12), 2788-2796. http://dx.doi.org/10.13675/j.cnki.tjjs.2017.12.018. (in Chinese)

[15] Bi, D, P.; Zhao, Y.; Guan, Q, L.; Xuan, W, W.; Zhang, J, S.; Modeling slag behavior in membrane wall gasifier, CIESC Journal 2015, 66(03), 888-895. http://dx.doi.org/10.11949/j.issn.0438-1157.20141321. (in Chinese)

[16] Chen, C.; Horio, M.; Kojima, T.; Numerical simulation of entrained flow coal gasifiers. Part I: modelling of coal gasification in an entrained flow gasifier, Chemical Engineering Science, 2000, 55(18):38613874. https://doi.org/10.1016/s0140-6701(02)80361-7

[17] Bi, D.; Guan, Q.; Xuan, W.; Zhang, J., Numerical simulation of GSP gasifier under different swirl angles, Fuel, 2015155-163. https://doi.org/10.1016/j.fuel.2015.04.001 
[18] Galvan, S.; Reggio, M.; Guibault, F. Assessment Study of K- $\varepsilon$ Turbulence Models and Near-Wall Modeling for Steady State Swirling Flow Analysis in Draft Tube Using Fluent, Engineering Applications of Computational Fluid Mechanics 2011, 05(04), 459-478. https://doi.org/10.1080/19942060.2011.11015386

[19] Xiao, X.J. Levying tariff or resource tax: The analysis about impact on Chinese rare earth industry. Journal of Mechanical Engineering Research and Developments, 2016. 39(4), 910-915. (in Chinese)

[20] Singh., G., N.; Khalid., M.; Effective Estimation Strategy of Population Variance in Two-Phase Successive Sampling Under Random Non-response, Journal of statistical theory and practice, 2019, 13(1). https://doi.org/10.1007/s42519-018-0010-y

[21] Dong, X, H.; Xue, Y, M.; Li, Q.; Chen, Z, Q.; Liang, X, X.; Chang, Y, M.; Wang, G, S.; National standard GB/T 94252012Testing method for work zone of heat treatment furnace explanation and practice, Heat Treatment of Metals 2015, 40(03), 214-220. http://dx.doi.org/10.13251/j.issn.02546051.2015.03.050. (in Chinese)

Submitted: $\quad 27.7 .2017$

Accepted: $\quad 27.3 .2019$
Hong-Xia Chen

Guang-Jun Jiang $\bowtie$

Le Gao

College of Mechanical Engineering, Inner Mongolia University of Technology, Hohhot, Inner Mongolia, 010051, P.R. China

Corresponding Author e-mail: jiang2003@imut.edu.cn 